\title{
Psychosocial Factors Correlated with Sufficient Consumption Behavior of Students in Thailand and Malaysia
}

\author{
Saran Pimthong ${ }^{1}$ \\ ${ }^{1}$ Behavioral Science Research Institute, Srinakharinwirot University, Bangkok, Thailand \\ Correspondence: Saran Pimthong, Behavioral Science Research Institute, Srinakharinwirot University, Bangkok \\ 10110, Thailand. E-mail: saranpimthong@gmail.com
}

Received: September 4, $2014 \quad$ Accepted: November 2, $2014 \quad$ Online Published: January 14, 2015
doi:10.5539/ass.v11n4p169

\begin{abstract}
The purpose of this study was to examine and compare the structural equation model of psychosocial factors related to sufficient consumption behavior between students in Thailand and Malaysia. For the sample of this study, 364 undergraduate students from Thailand and 360 from Malaysia were recruited, a total of 724 students. A series of 8 structured questionnaires with summated rating scales and 1 questionnaire on demographic characteristics were used to measure the aforementioned constructs of the hypothesized model. The findings are as follows: 1) The structural equation model of sufficient consumption behavior of the Thai and Malaysian students was adjusted. The sufficient consumption behavior was directly affected by materialism (-.54), attitude towards sufficient consumption behavior (.37), and character strengths (.21). The total causal variables accounted for $89 \%$ of the variance in the students' sufficient consumption behavior. 2) There was a difference in the structural model of the causal factors between students in Thailand and Malaysia. The direct effect of future orientation \& self control on their attitude towards sufficient consumption behavior was different, showing that the effect of students from Malaysia (.70) was higher than that of students from Thailand (.17). 3) Latent means of sufficient consumption behavior, attitude towards sufficient consumption behavior, materialism, future orientation \& self control, character strengths, family upbringing, peer influence, and media influence among Malaysian students scored higher than the Thai students.
\end{abstract}

Keywords: cross cultural research, sufficient consumption, Thai, Malaysian

\section{Introduction}

In the past several decades, the Southeast Asian region has experienced escalating economic growth. From urban expansion to industrial-driven developments, each country has witnessed tremendous changes in its social and cultural structure. Consequentially, commercial competitiveness and consumerism become unavoidable. Such changes result in the birth of consumption values that significantly affect both social and cultural structures (McGregor, 2013). In the meantime, consumerist culture has reached every class, gender and age of the population, particularly, the youth. Increasingly, children and teenagers have become prime target groups of consumer products, making purchases mainly out of their curiosity and lack of life experience. In the Thai context, reports have been done on excessive consumption behavior of students, for instance, on the continually increasing usage of mobile phones. A report on children and teenagers reveals that the percentage of elementary school students who use mobile phones is as high as $35.83 \%$ while the percentage of users in high school and university climbs up to 63.24 (Provincial Child Watch, 2006). A survey done on the food consumption behaviors of the Thai population indicates that more than $40.0 \%$ of Thai teenagers and young adults (15-24 years of age) engage in risky eating behaviors such as consuming foods high in fat, snacks, or sodas, with a frequency of up to 3-4 days per week (Thailand National Statistical Office, 2009).

How teenagers spend their free time is also another issue worth looking into. Spending free time creatively can be beneficial for both the teenagers themselves and the society as a whole. In Thailand, teenagers often use the Internet to browse for information, products, and services (79.6\%); to play and download games (65.4\%); to access news, and read newspapers and magazines (57.4\%); to download movies and music, watch television and videos, and listen to the radio (56.4\%); and to correspond via email (55.9\%). This reflects how Thai children and teenagers use the Internet: Primarily, they access entertainment materials, with education being much less prominent a motive (Office of the Promotion and Protection of Children, Youth, the Elderly and Vulnerable 
Groups, 2013).

A survey on the excessive consumption behaviors of Malaysian teenagers by Sorrooshian and Teck (2014), they found that over $45 \%$ of the students chose to spend their money on shopping and recreational activities and $60 \%$ on mobile phones, with prices ranging from 600-2,000 Malaysian Ringgit (approximately 6,000-20,000 baht), which is a considerably high price for students with no income of their own. In addition, $33 \%$ of the students show personal preferences for expensive clothes and accessories and more than $40 \%$ believe that money is the most important factor in life (Sorrooshian \& Teck, 2014). The obtained data are in accordance with the study by Kamaruddin and Mokhlis (2003), which indicates that the largest proportion of everyday spending of Malaysian teenagers is on clothes, makeup, food, athletic equipment and entertainment. This goes in the same direction with the research done by Ahmed, Ghingold and Zainurin (2007), who studied Malaysian teenagers' attitudes towards product consumption. Regarding spending behavior, their research reveals the majority of the sample group's salary is spent on entertainment and recreation in department stores.

Social Cognitive Learning Theory by Bandura (1986) believes that an individual's behavior is the acquisition conceived from interactions between the person and social environment. The theory proposes 'Person' and 'Environment' as the causes of an individual's behaviors. Studies in related concepts and theories finds that personal factor such as 'Future orientation and self-control' is a significant cause of individual's desirable behaviors (Bhanthumnavin, 1995; Ubonsai, 2012). Consequentially, such conceptual thinking influences the individual's sufficient consumption behavior for it involves the ability to critically speculate and acknowledge the importance of future (Mahoney \& Thoresen, 1974), for instance learning how to effectively save money in the coming times. 'Character strengths' is another personal factor with potential impact on an individual's positive behaviors. Having good personality is comparatively similar to having a positive trait, which reflects the individual's way of thinking and behaviors (Peterson \& Park, 2006). Several past researches show that a person with character strengths has greater tendency to have successful behaviors (Weber \& Ruch, 2012a; Weber \& Ruch, 2012b; Proctor et al., 2011).

The facts involving excessive consumption behaviors among children and teenagers illustrate how present youth consumption culture is conceived from psychological fulfillment rather than physical (Richins \& Dawson, 1992; Wong, 1997). Consumer culture has significant impact on young individuals' consumption demands (The United Nations, 2003), reflecting 'Materialism' as an important part of life values. This personal factor is the key element utilized in the forecast of sufficient consumption behavior, which is what this research attempts to explore.

Attitude can influence an individual's behaviors more than other type of psychological characteristic for it is the person's individually conceived notions towards different things (Shaver, 1981). Since attitude is the result of learning and can be changed, a youth's positive attitude towards sufficient consumption behavior reflects his or her thought, realization and belief in its good and benefits (Inthasuwan, 2007). This consequentially leads to personal preference, contentment and readiness to set up new pattern of consumption behavior. For that reason, it is believable that positive attitude can significantly influence an individual's consumption behaviors.

As for the aspect of 'situation' or 'environment, Social Cognitive Learning Theory believes that most people's behaviors are the outcomes of 'Observational Learning' or 'Modeling'. The key environmental factors influencing children and teenagers are, therefore, being studied in this research and categorized into family upbringing (Longres, 1995; Parker \& Benson, 2004), peer influence (Kirk, 2000; Burns \& Darling, 2002) and media influence (Anderson et al., 2003; Singer \& Singer, 2001). The impact of such environmental factors on youth consumption behaviors can also be found in other relevant researches (e.g. Story, Neumark-Sztainer, \& French, 2002; Chaplin \& John, 2010; Huang, Wang, \& Shi, 2012).

The conceptualized notion from Social Cognitive Learning Theory and critical analysis of involved research documents in both personal and environmental factor, collectively, reaffirm excessive consumption behaviors among the sample groups of Thai and Malaysian teenagers. Considering the fact that Thailand and Malaysia are important members of ASEAN community and neighbor countries with several economic, social and geographical similarities, the study of mental and social factors influencing sufficient consumption behaviors of Thai and Malaysian youth can be greatly beneficial. The research is done in the form of a cross-cultural study using statistical methods to compare and present the data for better clarification and understanding. By studying the possibilities of the hypothesis used in predicting students' consumption behavior, a comparative approach is employed to analyze the behaviors of the Thai and Malaysian students. The clarification of the variables' differences and universality, which are the focus of the study, will be used as the foundation in a behavioral development plan for children for the coming of the ASEAN Economics Community (AEC). 


\section{Objectives of the Research}

1) To develop a structural equation model of the sufficient consumption behavior of Thai and Malaysian students.

2) To determine the model invariance by comparing the model of sufficient consumption behavior of Thai and Malaysian students.

3) To conduct a comparison of the means of the latent variables of Thai and Malaysian students.

\section{Research Framework}

Social cognitive learning theory by Bandura (1986) is employed to draw the research framework. The theory explains how learning conceived from the interactions between learners and the social environment can be categorized as either observational learning or modeling. The main causes of human behaviors are conceived mainly from personal and environmental causes. The proposed research framework showing the hypothesized relationships among variables is represented in Figure 1.

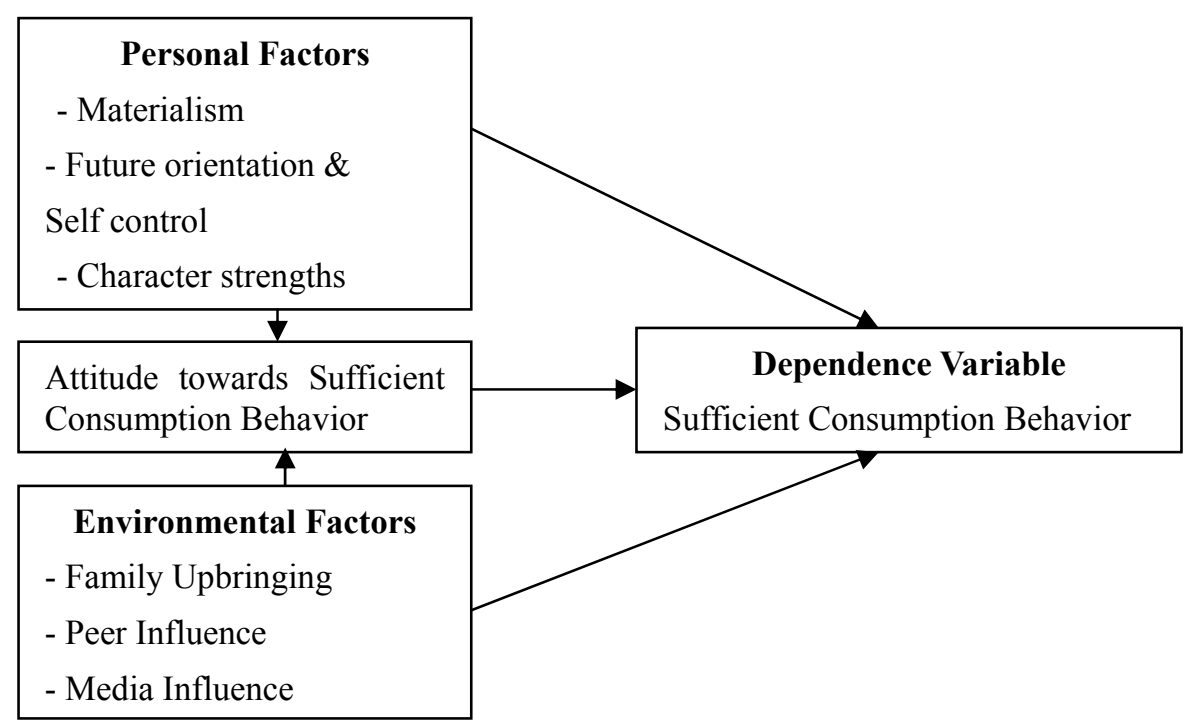

Figure 1. Hypothesized research framework

\section{Research Hypotheses}

1) The structural equation model of sufficient consumption behavior of Thai and Malaysian students is in accordance with the obtained empirical data.

2) The relations between the observed indicators of sufficient consumption behavior construct and the hypothesized effects among latent constructs are invariant across Thai and Malaysian students.

3) There are differences in the latent variables' mean in the structural equation model of sufficient consumption behavior between Thai and Malaysian students.

\section{Research Methodology}

\subsection{Participants and Sampling Procedures}

Bachelor's degree students from Thailand and Malaysia constitute the sample group of this research, with the Thai students coming from public universities in Bangkok and the Malaysian students from the International Islamic University of Malaysia (IIUM), which has been in academic collaboration with the Behavioral Science Research Institute at Srinakharinwirot University for a considerable period of time. To ensure the accuracy of sampling and the consequent validity of data analysis, Stratified Random Sampling is employed. The variables of the sampling are the college year and faculty of the participants. Simple Random Sampling is later conducted with students from different universities. The sampling is done with 364 samples taken from the Thai participants and 360 from the Malaysian participants, yielding a total of 724 samples. This number of samples is in accordance with the criteria to conduct the analysis of structural equation model with latent variables (Madden \& Dillion, 1982; Tabachnic \& Fidell, 1996). 


\subsection{Materials and Procedure}

The study uses 8 different tests to measure the variables and 1 questionnaire to obtain the participants' biosocial and social backgrounds. Most of these tests are revised and improved versions adapted from high validity standardized tests. Certain adjustments were made in order for the test and the questionnaire to suit the student participants. The tests and the questionnaire were written in two languages: a Thai version for Thai students and an English version for Malaysian students.

All tests are in a summated Likert scale, with the 6 rating scales ranging from 'Very true of me' to 'Very untrue of me'. Every test is calculated for content validity, in which an examination is done on the specification of the topic following each variable's operational definition. The content is submitted to and inspected by qualified experts. The test is later given to 100 bachelor's degree students from universities in Bangkok for conducting an item analysis using Item discrimination and item-total correlation. The reliability of each test is also calculated. All instruments were reliable with Cronbach's alpha scores ranging from 0.63 to 0.90 .

The following section describes the instrument for each of the study variable.

Sufficient Consumption Behavior The measure consisted of 15 items that measured 3 construct of things to consume, which were: (a) personal belongings, (b) common property resources, and (c) times. Items included were such as-"I stop eating when I feel full because eating too much can cause more harm than good".

Attitude towards Sufficient Consumption Behavior The measure consisted of 12 items that measured 3 components of attitude, which were: (a) cognitive, (b) affective, and (c) behavioral. Items included were such as-"I think living sufficiently with minimal lavishness is beneficial".

Materialism The construct questionnaire was based on the scale by Richin \& Dawson (1992). The 12 items, on a 6 point Likert scale, included "I admire people who own expensive homes, cars, and cloths".

Future orientation \& Self-control This was measured by 10 items. The self report items were measured on three dimensions; foresee ability, importance of future consciousness and self-control. Items included statements such as, "I am determined to focus on my study from today, for a better future in the days ahead".

Character strengths Fifteen items on the construct were adapted from the Values in Action Inventory of Strengths (VIA-IS) by Peterson \& Seligman (2004). The instrument was modified from 5 point to 6 point Likert scale and consisted of items such as "Being able to come up with new and different ideas is one of my strong points".

Family Upbringing The construct questionnaire was the 10 items, included "My parents rarely have time for me".

Peer Influence The measure consisted of 10 items that measured influence when a peer group, or individual encourages another person to change their ideals, or behaviors. Items included were such as-"I usually follow my friend when I don't know how to do".

Media Influence This was measured by 8 items. The self report items were measured about media influence on teenagers. Items included statements such as, "I think exposure to media increases my buying behavior and overall consumption".

\subsection{Data Analyses}

The LISREL program was used to test the hypothesis and interpret the content data. Confirmatory factor analysis was conducted to obtain construct validity. There were 9 fit measures to examine the goodness of fit of the model and empirical data (Diamantopoulos \& Siguaw, 2000; Hair et al., 2006).

\section{Results}

\subsection{Descriptive Analysis}

Descriptive statistics of both samples from Thailand and Malaysia are shown in Table 1. There were more females in the Thai (69.2\%) and Malaysian (82.5\%) sample. When the students' present their field of study, it was found that a majority or $49.2 \%$ of the Thai students and $52.8 \%$ of the Malaysian students are in the humanities or social sciences. In terms of education level, most students are in the second-year level. They accounted for $38.5 \%$ of the Thai sample while Malaysian accounted for $35.3 \%$. In the Thai sample there were around $59.9 \%$ students living with parent or family member, while in the Malaysian sample there were $52.8 \%$ living with friend or roommate. Mean age of both samples was around 21 years. 
Table 1. Demographic characteristics of the research samples

\begin{tabular}{lllll}
\hline Characteristics & $\begin{array}{l}\text { Thailand } \\
\text { Frequency }\end{array}$ & Percentage & $\begin{array}{l}\text { Malaysia } \\
\text { Frequency }\end{array}$ & Percentage \\
\hline $\mathrm{N}=$ & 364 & & 360 & \\
Gender & & & & 17.5 \\
1. Male & 112 & 30.8 & 63 & 82.5 \\
2. Female & 252 & 69.2 & 297 & 52.8 \\
Field of study & & & & 38.9 \\
1. Humanities or social sciences & 179 & 49.2 & 190 & 8.3 \\
2. Applied sciences & 120 & 32.9 & 140 & \\
3. Health sciences & 65 & 17.9 & 30 & 34.7 \\
Class year & & & & 35.3 \\
1. First-year & 41 & 11.3 & 53 & 18.9 \\
2. Second-year & 140 & 38.5 & 127 & \\
3. Third-year & 67 & 18.4 & 112 & 44.7 \\
4. Fourth-year or above & 116 & 31.8 & 68 & 52.8 \\
Live with & & & & 2.5 \\
1. Parent or family member & 218 & 59.9 & 161 & \\
2. Friend or roommate & 72 & 19.8 & 190 & \\
3. Alone & 74 & 20.3 & 9 & \\
Age & & & 21.62 & \\
1. Mean & 21.23 & & 1.50 & \\
2. SD & 1.21 & & & \\
\hline
\end{tabular}

Note: "Thailand"= Thai students, $\mathrm{N}=364$; "Malaysia= Malaysian students, $\mathrm{N}=360$

\subsection{A Structural Equation Model of the Sufficient Consumption Behavior}

The hypothesized model of sufficient consumption behavior of Thai and Malaysian students was tested by latent variable path analysis. The fit of hypothesized model was good $\left(\chi^{2}=402.06, \mathrm{df}=103(\mathrm{p}<.05), \mathrm{SRMR}=.065\right.$, $\mathrm{RMSEA}=.063, \mathrm{GFI}=.94, \mathrm{NFI}=.94, \mathrm{CFI}=.96, \mathrm{TLI}=.94, \mathrm{AGFI}=.90, \mathrm{PNFI}=.63$ and $\left.\chi^{2} / \mathrm{df}=3.903\right) . \mathrm{As}$ shown in Figure 2, all path coefficients were significant at .05. This illustrates that students' sufficient consumption behavior are directly influenced by the causal variables, listed in ascending order: materialism (standardized effect $=-.54$ ), attitude towards sufficient consumption behavior (standardized effect $=.37$ ), and character strengths (standardized effect $=.21$ ). The total causal variables accounted for $89 \%$ of the variance in the students' sufficient consumption behavior.

The attitude towards sufficient consumption behavior is directly influenced by the causal variables, arranged in the following ascending order: materialism (standardized effect $=-.85$ ), and future orientation and self-control (standardized effect $=.37$ ). The post-adjustment model gives out interesting data analysis results in addition to the research hypothesis; that is, the materialism variable is directly influenced by the causal variable. The results can be arranged in the following ascending order: media influence (standardized effect $=-.55$ ), peer influence (standardized effect $=-.21$ ), and family upbringing (standardized effect $=-.13$ ).

All of these results indicated that attitude towards sufficient consumption behavior and materialism played as mediator role between the personal and environmental factors on students' sufficient consumption behavior.

\subsection{Invariant across Thai and Malaysian Students}

The model invariance is determined by comparing the baseline model of no any parameter constraints to be equal across the groups to successively more restrictive models. A model whose $\chi 2$ is not significant different from the baseline model is deemed invariant and thus the constrained parameters in that model are considered equivalent across group. The invariant model will become baseline model for the next more restrictive model. Equivalence of measurement relationships among the observed indicators with Thai and Malaysian students' sufficient consumption behavior construct was found that all the effects in the hypothesized model were equivalent across two samples. There was one result that differed from that of total sample path analysis. The 
direct effect of future orientation \& self control on their attitude towards sufficient consumption behavior was different, showing that the effect of students from Malaysia (standardized effect $=.70$ ) was higher than that of students from Thailand (standardized effect $=.17$ ). All standardized effects were presented in Figure 3 .

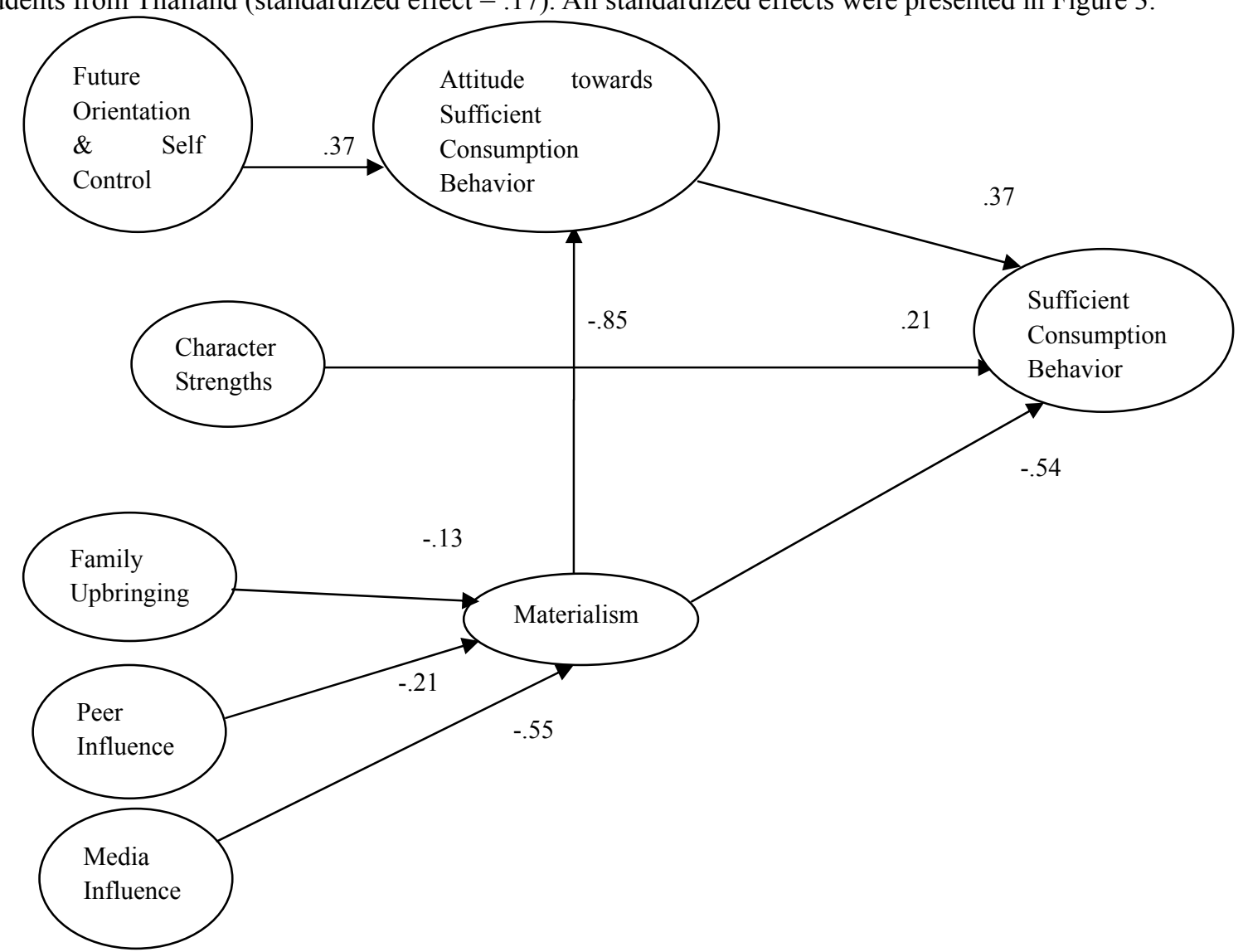

Figure 2. The hypothesized model of sufficient consumption behavior of Thai and Malaysian students

Note: The model represents the factors in the latent variable.

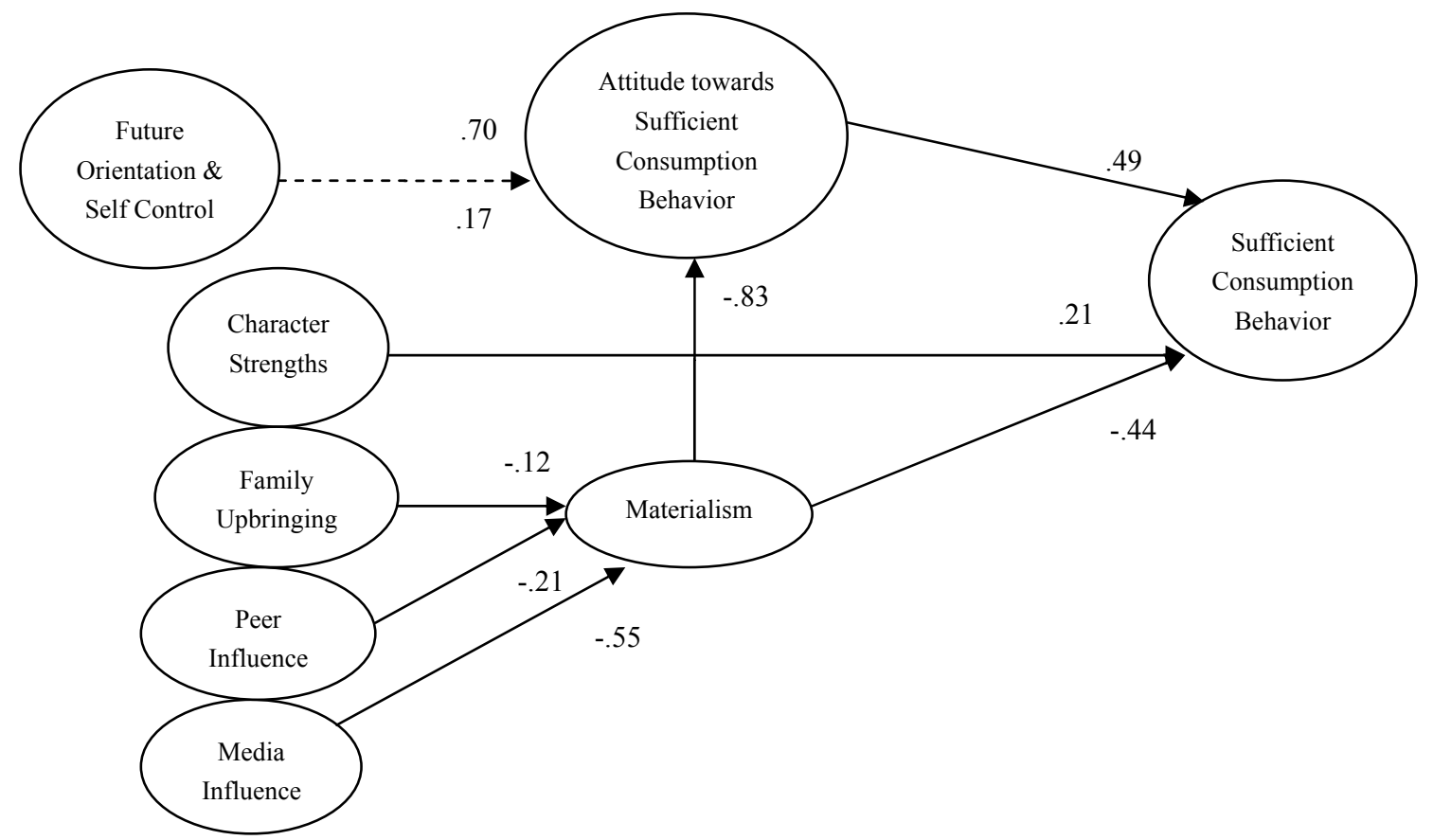

Figure 3. Standardized effects of multiple group path analysis results ( $\ldots \rightarrow$ indicate the model invariance) Note: The model represents the factors in the latent variable. 


\subsection{Latent Variable Mean Comparison}

Analysis was also conducted for latent variable mean comparison between the Thai and Malaysian sample groups. It was found that the latent means of sufficient consumption behavior, attitude towards sufficient consumption behavior, materialism, future orientation \& self control, character strengths, family upbringing, peer influence, and media influence among Malaysian students scored higher than the Thai students as shown in table 2. All mean differences were significant at .05.

Table 2. Latent variable mean comparison between the Thai and Malaysian students

\begin{tabular}{ll}
\hline Latent variable & Mean comparison \\
\hline Sufficient consumption behavior & $.19(\mathrm{t}=4.25)$ \\
Attitude towards sufficient consumption behavior & $.06(\mathrm{t}=2.62)$ \\
Materialism & $.10(\mathrm{t}=2.03)$ \\
Future orientation \& self control & $2.69(\mathrm{t}=21.34)$ \\
Character strengths & $.46(\mathrm{t}=10.99)$ \\
Family upbringing & $.69(\mathrm{t}=10.76)$ \\
Peer influence & $.62(\mathrm{t}=8.81)$ \\
Media influence & $.53(\mathrm{t}=7.49)$ \\
\hline
\end{tabular}

\section{Discussion}

The causal relationships among the variables of sufficient consumption behavior model of university students in Thailand and Malaysia were supported by the empirical data. Findings of the current study suggest that attitude towards sufficient consumption behavior mediated the relationships between the personal factor (future orientation \& self control) and sufficient consumption behavior; materialism mediated the relationships between the environmental factor (family upbringing, peer influence, and media influence) and sufficient consumption behavior. It is also found that most paths of relationship in the causal relationships model follow the research hypothesis. The results confirm the important effects of attitude on consumption behavior, which clearly reaffirm this particular research hypothesis. The study in this particular part is in accordance with the previous studies on Thai (Promlakano, 2006; Inthasuwan, 2007) and Malaysian students (Falahati, Paim, Ismail, \& Haron, 2011).

The effects of materialism on sufficient consumption behavior are in accordance with the past researches done on Thai (Meesakul, 2009; Phaisanpanich, 2012) and Malaysian students (Fah, Foon, \& Osman, 2011). The findings also indicate that materialism has an indirect effect on sufficient consumption behavior through the students' attitude towards sufficient consumption behavior variables. It suggests that students who do not glorify material wealth as their life achievement tend to uphold a personal belief that sufficient consumption behavior is a constructive conduct. Ultimately, they feel content, satisfied and ready to follow what they believe to be suitable consumption behavior. The research findings also show that future orientation and self-control have an indirect effect on sufficient consumption behavior though the attitude towards sufficient consumption behaviors' variables. It reflects the students' ability to potentially anticipate and acknowledge the positive prospects in their future, including the capability of self-control, being able to adapt their own behaviors.

Additionally, it is also discovered that character strengths have a direct effect on sufficient consumption behavior. The study in this particular part of the research is in accordance with the past researches conducted on a great variety of sample groups of young participants (Weber \& Ruch, 2012a; Weber \& Ruch, 2012b; Shoshani \& Slone, 2013; Seligman et al., 2009; Proctor et al., 2011). It shows that once the students possess character strengths, their psychological factors help enhance positive development in their way of life. This is because the concept of character strengths views good characteristics as a positive psychological characteristic that reflects the youths' thoughts, feelings and behaviors (Peterson \& Park, 2006).

The analyzed data also indicate that the three environmental factors have a direct effect on the materialism variable. The result is in accordance with the past researches such as the study conducted on family upbringing (Ahuvia \& Wong, 2002; Chaplin \& John, 2010), peer influence (Chan \& Prendergast, 2007; Chaplin \& John, 2010), and media influence (Buijzen \& Valkenburg 2003; Chan \& Prendergast, 2007). This shows the importance of environmental factors affecting materialism values among the youths, which also indirectly influences their sufficient consumption behavior. Such findings follow what Bandura (1986) had proposed on how the learning process of most persons is by observation or imitation through interactions one has with his/her surrounding 
environment. Imitation from modeling such as family, peer, or media as environmental factors, therefore, has significant effects on both the thoughts and actions of children and teenagers.

Data analysis shows that Malaysian students with increasing tendency of future orientation \& self control consequentially have more positive attitude towards sufficient consumption behavior than Thai students. This finding can be utilized as the point of discovery and observation for governmental agencies whose roles involve initiation and implementation of education policies in Thailand. This is because the key differences in psychological variables in Thai youths when compared to Malaysian youths distinctively reveal that Thai youths require basic psychological characteristic development in future orientation. If looking at Malaysia's national education policies, one can see that the policies have been initiated as a crucial part of the national development plan. The Malaysian Government has always regarded education policy as one of the most important factors in the country's development. In the meantime, Malaysia's education management highlights students' excellence as the main objective, prospectively reflecting the significant role of education in the country's future development plan. The clarification in the Malaysian Government's policies and visions in becoming a developed nation is one of the factors that stimulate the awareness among the Malaysian pupils. It consequentially results in the young Malaysians' ability to mature into visionary individuals, who foresee the importance of what can be beneficial for themselves and their country with great determination and patience. It also results in their capability to have self control and follow their goals with great tenacity for the even bigger and more important end results in the future such as the dedication in education that can help one become a part of the country's future development.

In the case of Thailand, there is a significant lack of consistency in the implementation of education policies, mainly due to the unsettling political situation. The lack of continuity in education management has excluded the youths from being made aware of the government's vision for the country's development plans. The implementation of policies also tends to be more quantitative rather than qualitative. These factors become negative effects on the quality of education and youth development. It is therefore extremely crucial for every involved sector to continually and seriously become a part of the long-term solution of Thailand's education dilemmas.

The all latent variables mean of the Malaysian students from the sample group is higher than those of Thai students. The author believes that such variation is the result of cultural differences and a dissimilarity of values between Thais and Malaysians, which significantly affect the behaviors being studied in the research. From the review of the literature and past academic work, no research has been conducted on cultural differences and dissimilarities of values of the youths in ASEAN countries. Nevertheless, there are results from the research done by Hofstede (1980, 1983, 1984, 1991, 1997, 2001 cited in Jandt, 2010) which studied the workplace values of IBM employees in over 40 countries and found that there are differences in values between employees from different races. The differences can be categorized into 4 dimensions: Individualism, Masculinity, Power distance, and Uncertainty avoidance. The comparative values of sample groups in Thailand and Malaysia are given a special emphasis, while the author selectively compares the values that involve the subjects' consumption behaviors' Individualism (the interest of the individual prevails over the interests of the group) and Masculinity (competitiveness, affirmation, ambition, materialism, accumulation of wealth). The study results show that Malaysians from the sample group possess more individualism and masculinity values than Thais.

From Hofstede's study, it is distinguishable that Thai and Malaysian employees from the sample group manifest distinctive cultural differences and dissimilarities of values. Consequently, such differences greatly affect the variables being studied in the research as all causal variables show significant connection with the youths' cultural and social values. Hofstede's study, therefore, can be used to comprehensibly support the results of this part.

\section{Suggestions}

The research results can be utilized beneficially as part of the policy formulation and guidelines by governmental agencies, the private sector, and private development organizations whose work revolves around the promotion and development of preferable behaviors among the youths. The aim is to nurture and encourage young citizens in becoming individuals with adequate consumption behavior, particularly, the following three developmental approaches in the psychological characteristic dimension: 1) Positive attitudes towards sufficient consumption behavior, in which the development helps the youths to believe in the sufficient consumption behavior as good and beneficial. The development aims to encourage the youths to be satisfied and determined to take what they believe to be the right path, while inspiringly motivating others to do the same. 2) Encourage the youths to acknowledge all the 3 dimensions of character strengths (Intelligent, Social and Emotional control). Such adaptation of positive psychology can help the youths to classify their strengths and use them to increase or 
maintain the level of moral and intelligent individuals in society. 3) Appropriately develop material values among the youths. The environmental factors that can significantly promote and enhance this particular aspect of development are family, peers, and the media.

\section{Acknowledgements}

This research was funded by the Behavioral Science Research Institute, at Srinakharinwirot University, Thailand.

\section{References}

Ahmed, Z. U., Ghingold, M., \& Zainurin, D. (2007). Malaysian shopping mall behavior: An exploratory study. Asia Pacific Journal of Marketing and Logistics, 9(4), 331-348. http://dx.doi.org/10.1108/13555850710 827841

Ahuvia, A. C., \& Wong, N. Y. (2002). Personality and Values Based Materialism: Their Relationship and Origins. Journal of Consumer Psychology, 12(4), 389-402. http://dx.doi.org/10.1207/15327660260382414

Anderson, C. A., Berkowitz, L., Donnerstein, E., Huesmann, R. L., Johnson, J., Linz, D., ... Wartella, E. (2003). The influence of media violence on youth. Psychological Science in the Public Interest, 4(3), 81-110.

Bandura, A. (1986). Social foundations of thought and action: A social cognitive theory. New Jersey: Prentice-Hall.

Bhanthumnavin, D. (1995). Psychological theory of moral and work behaviors: Research and applications. Bangkok: Graduate school of social development, National institute of development administration.

Buijzen, M., \& Valkenburg, P. M. (2003). The effects of television advertising on materialism, parent-child conflict, and unhappiness: A review of research. Applied Developmental Psychology, 24, 437-456. http://dx.doi.org/10.1016/S0193-3973(03)00072-8

Burns, A., \& Darling, N. (2002). Peer pressure is not peer influence. The Education Digest, 68(2), 4-6.

Chan, K., \& Prendergast, G. (2007). Materialism and social comparison among adolescents. Social Behavior and Personality, 35(2), 213-228. http://dx.doi.org/10.2224/sbp.2007.35.2.213

Chaplin, L. N., \& John, D. R. (2010). Interpersonal influences on adolescent materialism: A new look at the role of parents and peers. Journal of Consumer Psychology, 20, 176-184. http://dx.doi.org/10.1016/j.jcps.2010. 02.002

Diamantopoulos, A., \& Siguaw, J. A. (2000). Introducing LISREL. London: Sage Publications.

Fah, B. C. Y., Foon, Y. S., \& Osman, S. (2011). An exploratory study of the relationships between advertising appeals, spending tendency, perceived social status and materialism on perfume purchasing behavior. International Journal of Business and Social Science, 2(10), 202-208.

Falahati, L., Paim, L., Ismail, M., \& Haron, S. A. (2011). Factors Predict Financial Problem Among College Students: A Gendered View. Proceeding of 2011 International Conference on Sociality and Economics Development IPEDR, 10, 183-187.

Hair, J. F., Black, W. C., Babin, B. J., Anderson, R. E., \& Tatham, R. L. (2006). Multivariate Data Analysis (6th ed.). NJ: Pearson Education.

Huang, Y., Wang, L., \& Shi, J. (2012). How attachment affects the strength of peer influence on adolescent consumer behavior. Psychology \& Marketing, 29(8), 558-567. http://dx.doi.org/10.1002/mar.20543

Inthasuwan, P. (2007). The research and development of appropriate consumption behavior among Thai youth. Bangkok: The Behavioral Science Research Institute.

Jandt, F. E. (2010). An Introduction to Intercultural Communication: Identities in a Global Community (6th ed.). CA: Sage Publications.

Kamaruddin, A. R., \& Mokhlis, S. (2003). Consumer socialization, social structural factors and decision-making styles: A case study of adolescents in Malaysia. International Journal of Consumer Studies, 27(2), 145-156. http://dx.doi.org/10.1046/j.1470-6431.2003.00297.x

Kirk, A. M. (2000). Riding the bull: Reform in Washington, Kentucky, and Massachusetts. Journal of Health Politics, Policy and Law, 25(1), 133-173. http://dx.doi.org/10.1215/03616878-25-1-133

Longres, J. F. (1995). Human behavior in the social environment (2nd ed.). IL: F. E. Peacock.

Madden, T. J., \& Dillon, W. R. (1982). Causal analysis and latent class models: An application to a communication hierarchy of effects model. Journal of Marketing Research, 19, 472. http://dx.doi.org/10. 


\section{$2307 / 3151721$}

Mahoney, M. J., \& Thoresen, C. E. (1974). Self-control: Power to the person. CA: Brooks/Cole.

McGregor, S. L. T. (2013, July). Protecting children from the violence of consumerism: Educating for peace in a consumer society. Paper presented at the International Summer Course on the Rights of the Child, Université de Moncton, Moncton NB, Canada. Retrieved from http://www.consultmcgregor.com/ documents/research/moncton_rights_of_children_conference_consumer_violence.pdf

Meesakul, S. (2009). The development of validation of alienation in consumption culture model of students age between 13-18 years in Angthong province. Unpublished master's thesis. Srinakharinwirot University, Bangkok, Thailand.

Office of the Promotion and Protection of Children, Youth, the Elderly and Vulnerable Groups. (2013). Child and Youth Development Report for the year 2011. Bangkok: Ministry of Social Development and Human Security.

Parker, J., \& Benson, M. (2004). Parent-adolescent relations and adolescent functioning: Self-esteem, substance abuse, and delinquency. Adolescence, 39(155), 519-530.

Peterson, C., \& Park, N. (2006). Moral Competence and Character Strengths among adolescents: The development and validation of the Values in Action Inventory of Strengths for Youth. Journal of Adolescence, 29, 891-909. http://dx.doi.org/10.1016/j.adolescence.2006.04.011

Phaisanpanich, C. (2012). Influence of materialism and self-consciousness on generation Y's compulsive buying behavior. Unpublished master's thesis. Chulalongkorn University, Bangkok, Thailand.

Proctor, C., Tsukayama, E., Wood, A. M., Maltby, J., Eades, J. F., \& Linley, P. A. (2011). Strengths gym: The impact of a character strengths-based intervention on the life satisfaction and well-being of adolescents. The Journal of Positive Psychology, 6(5), 377-388. http://dx.doi.org/10.1080/17439760.2011.594079

Promlakano, D. (2006). Antecedent and consequences concerning student health behaviors of late adolescents in Health Promoting Schools Project. Unpublished master's thesis. National Institute of Development Administration, Bangkok, Thailand.

Provincial Child Watch. (2006). Child watch 2004-2005. Bangkok: Chulalongkorn University Printing House.

Richins, M. L., \& Dawson, S. (1992). A consumer value orientation for materialism and its measurement: Scale development and validation. Journal of Consumer Research, 19, 303-316. http://dx.doi.org/10.1086/209304

Seligman, M. E. P., Ernst, R. M., Gillham, J., Reivich, K., \& Linkins, M. (2009). Positive education: Positive psychology and classroom interventions. Oxford Review of Education, 35(3), 293-311. http://dx.doi.org/10. 1080/03054980902934563

Shaver, K. G. (1981). Principles of Social Psychology (2nd ed.). Cambridge: Winthrop Publishers.

Shoshani, A., \& Slone, M. (2013). Middle school transition from the Strengths Perspective: Young adolescents' character strengths, subjective well-being, and school adjustment. Journal of Happiness Studies, 14(4), 1163-1181. http://dx.doi.org/10.1007/s10902-012-9374-y

Singer, D. G., \& Singer, J. L. (2001). Handbook of Children and the Media. CA: Sage.

Sorooshian, S., \& Teck, T. S. (2014). Spending behaviour of a case of Asian university students. Asian Social Science, 10(2), 64-69.

Story, M., Neumark-Sztainer, D., \& French, S. (2002). Individual and environmental influences on adolescent eating behaviors. Journal of the American Dietetic Association, 102(3), S40-S51. http://dx.doi.org/10.1016 /S0002-8223(02)90421-9

Tabachnic, B. G., \& Fidell, L. S. (1996). Using Multivariate Statistics (3rd ed.). NY: Harper Collins.

Thailand National Statistical Office. (2009). The Executive Summary: The survey on health behavior of Thai population in 2009 (food consumption behavior). Retrieved September 1, 2014 from http://service.nso.go.th /nso/nsopublish/service/survey/healthCare_52.pdf

The United Nations. (2003). The World Youth Report 2003: The Global Situation of Young People. NY: United Nations Publications.

Ubonsai, K. (2012). Psychological characteristics and work situations as correlates of teachers' sufficiency economy socialization and its consequence on students' attitude toward teachers' sufficiency economy 
socialization. Unpublished master's thesis. Srinakharinwirot University, Bangkok, Thailand.

Weber, M., \& Ruch, W. (2012a). The role of character strengths in adolescent romantic relationships: An initial study on partner selection and mates' life satisfaction. Journal of Adolescence, 35(6), 1537-1546. http://dx.doi.org/10.1016/j.adolescence.2012.06.002

Weber, M., \& Ruch, W. (2012b). The role of a good character in 12-year-old school children: Do character strengths matter in the classroom? Child Indicators Research, 5(2), 317-334. http://dx.doi.org/10.1007/s 12187-011-9128-0

Wong, N. Y. (1997). Suppose you own the world and no one knows? Conspicuous consumption, materialism and self. Advances in Consumer Research, 24, 197-203.

\section{Copyrights}

Copyright for this article is retained by the author(s), with first publication rights granted to the journal.

This is an open-access article distributed under the terms and conditions of the Creative Commons Attribution license (http://creativecommons.org/licenses/by/3.0/). 